\title{
Antibiotic resistance and molecular characterization of the hydrogen sulfide- negative phenotype among diverse Salmonella serovars in China
}

Jing $\mathrm{Xie}^{1+}$, Fuli $\mathrm{Wu}^{1+}$, Xuebin $\mathrm{Xu}^{2+}$, Xiaoxia Yang ${ }^{1}$, Rongtao Zhao ${ }^{1}$, Qiuxia Ma', Peng Li', Ligui Wang ${ }^{1}$, Rongzhang Hao', Leiji Jia', Xinying Du', Shaofu Qiu ${ }^{1 *}$ and Hongbin Song ${ }^{1 *}$

\begin{abstract}
Background: Among 2179 Salmonella isolates obtained during national surveillance for salmonellosis in China from 2005 to 2013, we identified 46 non- $\mathrm{H}_{2}$ S-producing strains originating from different sources.

Methods: The isolates were characterized in terms of antibiotic resistance and genetic variability by pulsed-field gel electrophoresis and multilocus sequence typing. Mutation in the phs operon, which may account for the non- $\mathrm{H}_{2} \mathrm{~S}-$ producing phenotype of the isolated Salmonella strains, was performed in this study.

Results: Among isolated non- $\mathrm{H}_{2} \mathrm{~S}$-producing Salmonella strains, more than $50 \%$ were recovered from diarrhea patients, of which $\mathrm{H}_{2} \mathrm{~S}$-negative S. Gallinarum, S. Typhimurium, S. Choleraesuis and S. Paratyphi A isolates constituted $76 \% . \mathrm{H}_{2} \mathrm{~S}$-negative isolates exhibited a high rate of resistance to ticarcillin, ampicillin, and tetracycline, and eight of them had the multidrug resistance phenotype. Most $\mathrm{H}_{2} \mathrm{~S}$-negative Salmonella isolates had similar pulsed-field gel electrophoresis profiles and the same sequence type as $\mathrm{H}_{2} \mathrm{~S}$-positive strains, indicating a close origin, but carried mutations in the phsA gene, which may account for the non- $\mathrm{H}_{2} \mathrm{~S}$-producing phenotype.
\end{abstract}

Conclusions: Our data indicate that multiple $\mathrm{H}_{2} \mathrm{~S}$-negative strains have emerged and persist in China, emphasizing the necessity to implement efficient surveillance measures for controlling dissemination of these atypical Salmonella strains.

Keywords: Multidrug resistance, Hydrogen sulfide, Salmonella, Serogroup, phs operon

\section{Background}

Salmonella remains one of the most prevalent foodborne pathogens causing bacterial gastroenteritis $[1,2]$. Infection through contaminated food and water can lead to diarrhea and even death. It has been reported that Salmonella species can account for nearly 93.8 million cases of gastroenteritis every year worldwide, resulting in 155,000 deaths [3]. In China, Salmonella spp. are responsible for approximately $22.2 \%$ of foodborne diseases, resulting in 9.03 million cases and estimated 800 deaths annually [4]. Therefore, it is particularly important to

\footnotetext{
*Correspondence: qiushf0613@hotmail.com; hongbinsong@263.net ${ }^{\dagger}$ Jing Xie, Fuli Wu and Xuebin Xu contributed equally to this work. ${ }^{1}$ Institute of Disease Control and Prevention, Academy of Military Medical Sciences, 20 Dongda Street, Fengtai District, Beijing 100071, China Full list of author information is available at the end of the article
}

further strengthen the surveillance and control of Salmonella. As hydrogen sulfide $\left(\mathrm{H}_{2} \mathrm{~S}\right)$ production is characteristic of these pathogens, $\mathrm{H}_{2} \mathrm{~S}$ detection has become a screening method to identify and differentiate Salmonella from other intestinal bacteria [5]. However, $\mathrm{H}_{2} \mathrm{~S}$-negative Salmonella isolates have been continuously reported in different countries; thus, one isolate was identified in Kuwait, 10 in United States, 31 in Japan, and 58 in Southeast China [6-12]. In our previous studies, we also identified $43 \mathrm{H}_{2} \mathrm{~S}$-negative Salmonella isolates during national surveillance of salmonellosis in China [13-15]. These results suggest that the occurrence of the atypical $\mathrm{H}_{2} \mathrm{~S}$-negative Salmonella variants is growing throughout the world.

Increasing resistance of Salmonella to antibiotics, especially high prevalence of multidrug resistance (MDR), 
is a global concern. In many regions of the world, a high resistance rate to conventional antimicrobial agents has been reported for $\mathrm{H}_{2} \mathrm{~S}$-positive Salmonella [16-19]. Although $\mathrm{H}_{2} \mathrm{~S}$-negative Salmonella isolates may be highly sensitive to a multitude antibiotics owning to $\mathrm{H}_{2} \mathrm{~S}$ defending bacteria against oxidative stress imposed by antibiotics [20], there is increasing evidence that high resistance rate to antibiotics was also observed in many $\mathrm{H}_{2} \mathrm{~S}$-negative Salmonella isolates [6, 7, 14]. Importantly, extended-spectrum cephalosporins and fluoroquinolones have been widely used as alternative agents for treatment of salmonellosis. However, a non- $\mathrm{H}_{2} \mathrm{~S}$-producing S. Kentucky isolate had the MDR phenotype, including resistance to ciprofloxacin, whereas non- $\mathrm{H}_{2} \mathrm{~S}$-producing $\mathrm{S}$. Infantis and $S$. Typhimurium expressed CMY-2 $\beta$-lactamase and had reduced susceptibility to cefazolin $[6,8]$. These results may due to different bactericidal mechanisms of various classes of antibiotics. Taken together, it is important to pay more attention on the surveillance of $\mathrm{H}_{2} \mathrm{~S}$-negative Salmonella.

Salmonella spp. produce $\mathrm{H}_{2} \mathrm{~S}$ from various enzymes encoded by different operons, such as phs operon, cysJIH operon and asr operon [21-23]. However, the phs operon is essential for this activity in Salmonella [24]. Sakano et al. [8] detected a nonsense mutation in the phs $\mathrm{A}$ gene in $\mathrm{H}_{2} \mathrm{~S}$-negative $\mathrm{S}$. Infantis and $S$. Typhimurium isolates, and in our previous studies, we found more mutations in the phs $A$ gene of $\mathrm{H}_{2} \mathrm{~S}$-negative $S$. Senftenberg, S. Choleraesuis, and S. Aberdeen [13-15]. These data suggest that the disruption of the phs locus is responsible for the lack of $\mathrm{H}_{2} \mathrm{~S}$ production and incorrect identification of Salmonella. Here, we report the identification of $46 \mathrm{H}_{2} \mathrm{~S}$-negative Salmonella strains during the national surveillance of salmonellosis from 2005 to 2013 in China. Our findings indicate that various serovars of $\mathrm{H}_{2} \mathrm{~S}$-negative Salmonella have emerged in China. Therefore, effective measures should be urgently taken to prevent and control further dissemination of $\mathrm{H}_{2} \mathrm{~S}$-negative Salmonella in China.

\section{Methods}

\section{Isolation, identification, and serotyping of Salmonella} strains

In this study, Salmonella isolates were obtained during national surveillance for salmonellosis in China conducted from 2005 to 2013. Samples were collected in eight cities throughout China (Beijing, Nanjing, Shanghai, Guangzhou, Shenyang, Jinan, Xinjiang, and Yuxi) from various sources, including diarrhea patients, poultry, livestock, vegetables, aquatic products, and water. First, the samples were enriched by culturing in Selenite Brilliant Green broth (CHROMagar, Shanghai, China) at $37^{\circ} \mathrm{C}$ for $16-22 \mathrm{~h}$, and then plated on xylose lysine deoxycholate agar (XLD; CHROMagar) and CHROMagar Salmonella medium
(CAS; CHROMagar) at $37{ }^{\circ} \mathrm{C}$ for $18-24$ h. Colonies suspected to be formed by Salmonella were serotyped by slide agglutination tests (SSI Diagnostica, Hillerød, Denmark). API 20E test strips (bioMerieux Vitek, Marcy-l'Etoile, France) were used to confirm the identified colonies and examine for the $\mathrm{H}_{2} \mathrm{~S}$-producing phenotype.

\section{Antimicrobial susceptibility testing}

$\mathrm{H}_{2} \mathrm{~S}$-negative and $\mathrm{H}_{2} \mathrm{~S}$-positive Salmonella isolates were tested for sensitivity to 21 antibiotics used commonly in laboratories and hospitals. MICs of 21 antibiotics including amikacin, ampicillin, aztreonam, cefazolin, cefepime, cefoperazone, cefoxitin, ceftazidime, ceftriaxone, chloramphenicol, gentamicin, imipenem, levofloxacin, nitrofurantoin, norfloxacin, piperacillin, tetracycline, ticarcillin, ticarcillin-clavulanic acid, tobramycin, and trimethoprimsulfamethoxazole were evaluated by the automated broth microdilution method using 96-well microtiter plates (Sensititre; Terk Diagnostic Systems, Thermo Fisher Scientific Inc., Cleveland, OH, USA). The results were interpreted according to the recommendations of the Clinical and Laboratory Standards Institute (CLSI) [25] and Escherichia coli strain ATCC 25922 was used for quality control. Genetic variations related to molecular mechanisms responsible for the resistance to quinolones were examined by PCR. The specific primers were as follows: gyrA forward 5'-TTATGCGATGTCGGTCATTGTT-3' and reverse 5' -TTCACCAGCTCGGCGATT-3' and parC forward 5'-CGTGCGTTGCCGTTTATTG-3' and reverse 5' -CAACTGATCCAGCGTCGTT-3'.

\section{Multilocus sequence typing analysis}

Total DNA was extracted from the identified Salmonella isolates using the TIANamp Bacteria DNA kit (Tiangen Biotech, Beijing, China) according to the manufacturer's instruction, and MLST was performed using the protocol described in our previous study [13]. Sequences of seven housekeeping genes (aroC, dnaN, hemD, hisD, purE, sucA, and thrA) were downloaded from the MLST database. The sequences of PCR-amplified products were uploaded to http://enterobase.warwick.ac.uk/species/senterica/allele_st_search for comparison and analysis to determine the sequence type (ST).

\section{Pulsed-field gel electrophoresis analysis}

DNA was digested with $\mathrm{XbaI}$ (Takara, Dalian, Japan) at $37^{\circ} \mathrm{C}$ for $3 \mathrm{~h}$ and subjected to PFGE according to a standardized protocol [26]. Then, electrophoresis of the digested DNA was carried out using a CHEF Mapper PFGE system (Bio-Rad, Hercules, CA, USA) in 1\% SeaKem agarose and $0.5 \times$ Tris-borate-EDTA for $19 \mathrm{~h}$ with the following run parameters: $6 \mathrm{~V} / \mathrm{cm}$ and a linear increase in switching times from 2.16 to $63.8 \mathrm{~s}$. 
Macrorestriction patterns were compared and analyzed using the BioNumerics Fingerprinting software version 6.0 (Applied-Maths, Sint-Martens-Latem, Belgium). Dendrograms were constructed according to the unweighted pair-group method of arithmetic average (UPGMA), and the Disc coefficient of similarity was determined based on $1.2 \%$ position tolerance. $S$. Braenderup $\mathrm{H} 9812$ was used as a standard [27].

\section{Amplification and sequencing of the Phs operon}

The phs operon containing three open reading frames, designated $p h s A$, $p h s B$, and $p h s C$, which encode thiosulfate reductases catalyze thiosulfate to $\mathrm{H}_{2} \mathrm{~S}$. The phs operon ( $p h s A, p h s B$, and $p h s C$ ) was amplified by PCR and sequenced by Sangon Biotech. The specific primers were as follows: phsA1 forward 5'-CGTTGGATGCCTGT TCAG-3' and reverse 5' -AGGTCGTAGAGCCGATTG3', phsA2 forward5'-CGCCGTTCAACTGATAGA-3' and reverse 5'-AATGGTGAGCTTCGATCC-3', phsA3 forward 5'-CATCGTAGAGCTGTTCATCA-3' and reverse $5^{\prime}$-CATGTGCGTGTTCAGGAA-3', phsB forward 5'-CAAGCATGAGCAGCACCAC-3' and reverse 5'ATGAGGGAGGAGGGAACCAT-3', and $p h s C$ forward 5'-GATGGTCTCTATTTGCCGTTCT-3' and reverse 5'-GGTGCTGCTCATGCTTGTT-3'.

The PCR amplification conditions were as follows: PCR conditions were as follows: $95{ }^{\circ} \mathrm{C}$ for $5 \mathrm{~min}$; $30 \mathrm{cy}$ cles of $95{ }^{\circ} \mathrm{C}$ for $30 \mathrm{~s}, 57^{\circ} \mathrm{C}$ for $40 \mathrm{~s}$, and $72{ }^{\circ} \mathrm{C}$ for $45 \mathrm{~s}$; and $72{ }^{\circ} \mathrm{C}$ for $7 \mathrm{~min}$, using Ex Taq DNA polymerase (TaKaRa/Clontech). The results were imported into DNAman 6.0, and genetic differences were detected using MEGA version 7.0. Reference strains for phs operon sequence analysis are listed in Additional file 1: Table S1. For $S$. Derby and $S$. Meleagridis, the reference strains (S. Derby str. 91,780 and $S$. Meleagridis str. SH10SF424-1) were of the $\mathrm{H}_{2} \mathrm{~S}$-positive phenotype identified in this study.

\section{Nucleotide sequence accession numbers}

The nucleotide sequences obtained in this study have been deposited to the NCBI database; GenBank accession numbers are listed in Additional file 1: Table S2.

\section{Statistical analysis}

The data were analyzed by chi-square test using the SPSS software (SPSS Inc., Chicago, IL, USA; version $17.0)$, and a $P$-value $<0.05$ was considered to indicate statistically significant differences.

\section{Results}

\section{$\mathrm{H}_{2} \mathrm{~S}$-negative Salmonella isolates}

During national surveillance of salmonellosis in 20052013 in China, $46 \mathrm{H}_{2} \mathrm{~S}$-negative Salmonella isolates were identified among 2179 Salmonella strains from various sources. These strains were divided into 12 serovars: $S$. Gallinarum, S. Typhimurium, S. Choleraesuis, S. Paratyphi A, $S$. Meleagridis, $S$. Agona, $S$. Thompson, $S$. Enteritidis, S. Derby, S. Paratyphi B, S. Hadar, and S. Give (Fig. 1a). Among them, S. Gallinarum, S. Paratyphi A, $S$. Meleagridis, S. Agona, $S$. Thompson, $S$. Paratyphi B, $S$. Hadar, and $S$. Give were reported as having the non- $\mathrm{H}_{2} \mathrm{~S}$-producing phenotype for the first time. The most prevalent serovars for non- $\mathrm{H}_{2} \mathrm{~S}$-producing Salmonella were $S$. Gallinarum, S. Typhimurium, S. Choleraesuis and $S$. Paratyphi A, accounting for 33, 17, 13 and $13 \%$, respectively, of the entire collection. Twenty-four (52\%) samples were from humans with diarrhea, whereas 21 (46\%) were from animals, including pork, chicken, and aquatic products, and one $\mathrm{H}_{2} \mathrm{~S}$-negative isolate was recovered from the river. During the period from 2006 to 2009, only three $\mathrm{H}_{2} \mathrm{~S}$-negative isolates were identified; however, approximately $93 \%$ isolates were identified with a high level of detection in the following 4 years (Fig. 1b).

\section{Antimicrobial resistance among $\mathrm{H}_{2} \mathrm{~S}$-negative Salmonella}

Testing of the identified Salmonella isolates for antimicrobial susceptibility to 21 different antibiotics showed that they exhibited a high rate of resistance to conventional antimicrobial agents. $\mathrm{H}_{2} \mathrm{~S}$-negative isolates displayed high resistance to ampicillin, ticarcillin, tetracycline, tobramycin, chloramphenicol, gentamicin, and trimethoprim-sulfamethoxazole (Table 1); furthermore, quinolone-resistant and cefazolin-resistant strains were also detected.

Each serovar showed a distinct antibiotic resistance pattern (Table 1). Overall, $\mathrm{H}_{2} \mathrm{~S}$-negative $S$. Typhimurium isolates demonstrated resistance to 11 antibiotics, with a high resistance rate to penicillins and tetracyclines. For two quinolones-resistant $S$. Typhimurium isolates, multisite mutations were detected simultaneously in the gyrA and parC genes; polymorphisms at positions 200 and 250 may be responsible for the resistance to quinolones (GenBank accession numbers: KY814731-KY814732 and KY814737-KY814738). $\mathrm{H}_{2} \mathrm{~S}$-negative $\mathrm{S}$. Choleraesuis isolates displayed high resistance to tetracycline, ticarcillin, ampicillin, trimethoprim-sulfamethoxazole, chloramphenicol and gentamicin; importantly, all these isolates were from hospitalized diarrhea patients. About $80 \%$ of $\mathrm{H}_{2} \mathrm{~S}$-negative $S$. Gallinarum isolates were resistant to ticarcillin and ampicillin. In addition, $\mathrm{H}_{2} \mathrm{~S}$-negative $S$. Give, $S$. Derby, and $S$. Meleagridis were resistant to seven, three, and two antibiotics, respectively. All $\mathrm{H}_{2} \mathrm{~S}$-negative $S$. Paratyphi A, $S$. Paratyphi B, S. Enteritidis, S. Agona, S. Harder, and $S$. Thompson isolates were susceptible to the 21 tested antimicrobials.

Among the examined $\mathrm{H}_{2} \mathrm{~S}$-negative Salmonella, the MDR phenotype was observed in eight (17\%) isolates 


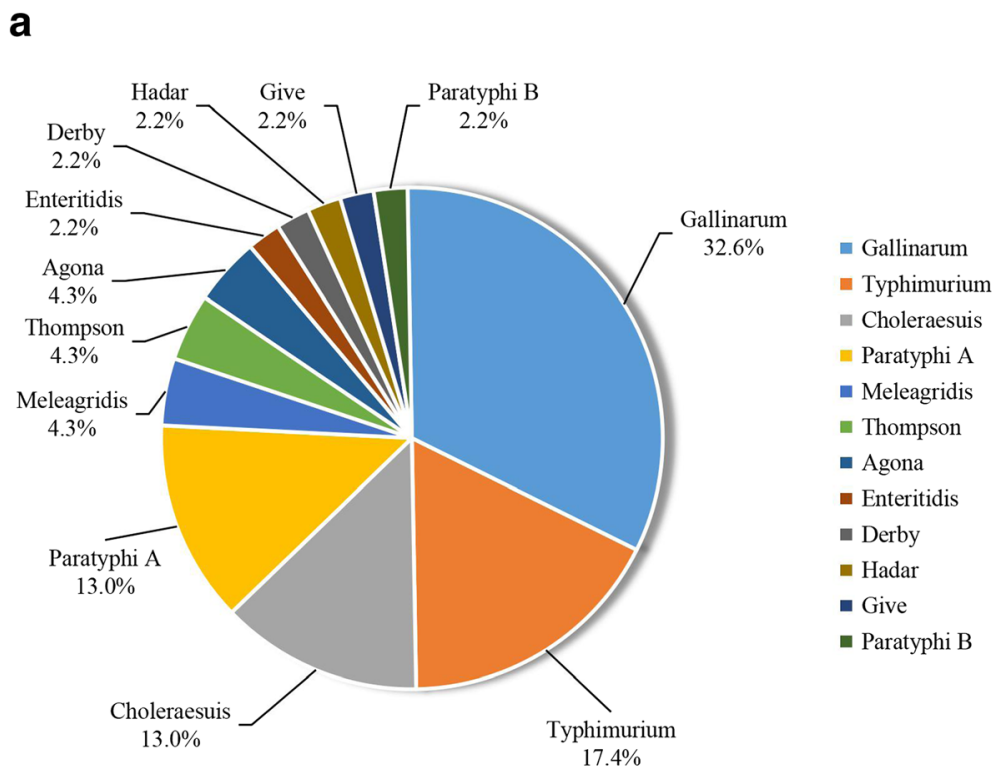

b

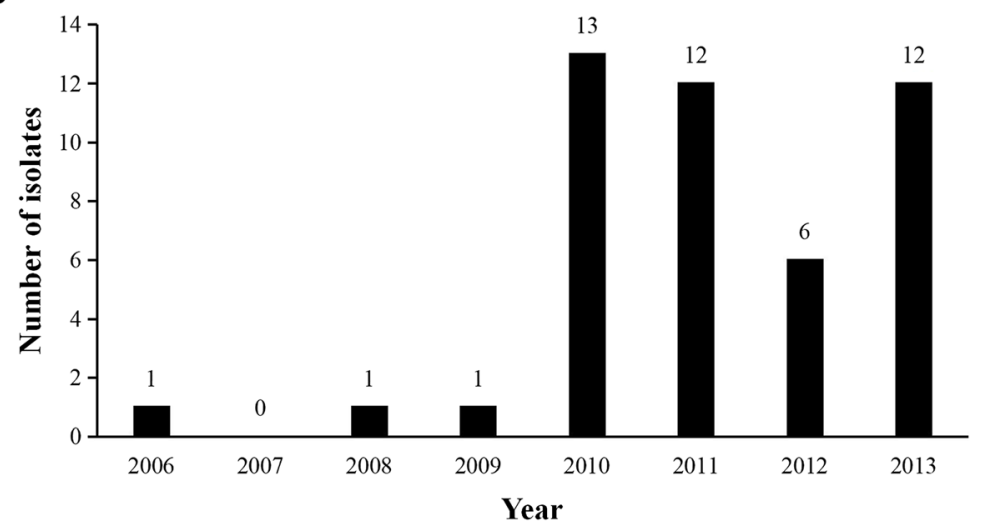

Fig. 1 Distribution of non- $\mathrm{H}_{2} \mathrm{~S}$-producing Salmonella isolates in China by serotype (a) and time of isolation (b)

(Table 2). The $\mathrm{H}_{2} \mathrm{~S}$-negative MDR strains showed seven distinct antibiotic-resistance profiles. Two MDR isolates identified as $\mathrm{H}_{2} \mathrm{~S}$-negative $S$. Typhimurium had the widest antibiotic-resistance profiles, showing resistance to more than six classes of antimicrobials, including 11 individual antibiotics. $\mathrm{H}_{2} \mathrm{~S}$-negative $\mathrm{S}$. Choleraesuis isolates displayed the highest MDR rate: 67\% (4 of 6). Among them, one isolate was resistant to five classes of antimicrobials, and the others were resistant to four classes. Moreover, $\mathrm{H}_{2} \mathrm{~S}$-negative $S$. Give and $S$. Derby isolates also had the MDR phenotype. The same proportions of $\mathrm{H}_{2} \mathrm{~S}$-negative MDR isolates (about $50 \%$ ) were recovered from humans and animals.

\section{PFGE and MLST analyses}

$\mathrm{H}_{2} \mathrm{~S}$-positive $S$. Gallinarum, $S$. Hadar, $S$. Paratyphi A, $S$. Paratyphi B, $S$. Choleraesuis, and $S$. Give isolates were not detected during national surveillance for salmonellosis in this study. For PFGE testing and MLST analysis, we combined $46 \mathrm{H}_{2} \mathrm{~S}$-negative and $29 \mathrm{H}_{2} \mathrm{~S}$-positive Salmonella isolates (four $S$. Derby, seven $S$. Enteritidis, four $S$. Agona, three $S$. Thompson, two $S$. Meleagridis, and nine $S$. Typhimurium) to clarify their genetic relationships. Cluster analysis divided the 75 isolates into three distinct groups sharing approximately $50 \%$ similarity (Fig. 2).

Group I consisted of four clusters. Cluster 1 contained two serovars: $S$. Derby and $S$. Enteritidis. $S$. Derby $\mathrm{H}_{2} \mathrm{~S}$-producing SH10SF170-1 and non- $\mathrm{H}_{2} \mathrm{~S}$-producing SH10SF170-2 had indistinguishable PFGE profiles, similar to $S$. Enteritidis SH11G52-1 and SH11G52-2. In cluster 2 , all isolates were from poultry and were identified as $\mathrm{H}_{2} \mathrm{~S}$-negative $S$. Gallinarum. Although these strains were acquired from different places at different times, they shared high similarity in their PFGE patterns. All $\mathrm{H}_{2} \mathrm{~S}$-negative $\mathrm{S}$. Gallinarum isolates belonged to ST92 except for one belonging to the new ST1961, which was a single locus variant (SLV) of ST92. Moreover, S. Agona $\mathrm{H}_{2} \mathrm{~S}$-negative 
Table 1 Antibiotic resistance patterns for various serovars of $\mathrm{H}_{2} \mathrm{~S}$-negative Salmonella isolates

\begin{tabular}{|c|c|c|c|c|c|c|c|}
\hline \multirow[t]{2}{*}{ Antimicrobial drugs } & \multicolumn{7}{|c|}{ Resistant isolates, \% (n) } \\
\hline & $\begin{array}{l}\text { Total } \\
(n=46)\end{array}$ & $\begin{array}{l}\text { Gallinarum } \\
(n=15)\end{array}$ & $\begin{array}{l}\text { Typhimurium } \\
(n=8)\end{array}$ & $\begin{array}{l}\text { Choleraesuis } \\
(n=6)\end{array}$ & $\begin{array}{l}\text { Meleagridis } \\
(n=2)\end{array}$ & $\begin{array}{l}\text { Derby } \\
(n=1)\end{array}$ & $\begin{array}{l}\text { Give } \\
(n=1)\end{array}$ \\
\hline Cefazidime & 0 & 0 & 0 & 0 & 0 & 0 & 0 \\
\hline Ceftriaxone & 0 & 0 & 0 & 0 & 0 & 0 & 0 \\
\hline Cefepime & 0 & 0 & 0 & 0 & 0 & 0 & 0 \\
\hline Cefoperazone & 0 & 0 & 0 & 0 & 0 & 0 & 0 \\
\hline Imipenem & 0 & 0 & 0 & 0 & 0 & 0 & 0 \\
\hline Nitrofurantoin & $2(1)$ & 0 & $13(1)$ & 0 & 0 & 0 & 0 \\
\hline Piperacillin & $4(2)$ & 0 & $13(1)$ & $17(1)$ & 0 & 0 & 0 \\
\hline Ticarcillin & $46(21)$ & $80(12)$ & $50(4)$ & $67(4)$ & 0 & 0 & $100(1)$ \\
\hline Ticarcillin-clavulanic acid & 7 (3) & $6(1)$ & $25(2)$ & 0 & 0 & 0 & 0 \\
\hline Ampicillin & $46(21)$ & $80(12)$ & $50(4)$ & $67(4)$ & 0 & 0 & $100(1)$ \\
\hline Tetracycline & $35(16)$ & $13(2)$ & $63(5)$ & $83(5)$ & $100(2)$ & $100(1)$ & $100(1)$ \\
\hline Cefazolin & $2(1)$ & $7(1)$ & 0 & 0 & 0 & 0 & 0 \\
\hline Cefoxitin & & 0 & 0 & 0 & 0 & 0 & 0 \\
\hline Aztreonam & & 0 & 0 & 0 & 0 & 0 & 0 \\
\hline Chloramphenicol & $15(7)$ & 0 & $25(2)$ & $50(3)$ & 0 & $100(1)$ & $100(1)$ \\
\hline Tobramycin & $2(1)$ & 0 & 0 & 0 & 0 & 0 & $100(1)$ \\
\hline Gentamicin & $13(6)$ & 0 & $25(2)$ & $50(3)$ & 0 & 0 & $100(1)$ \\
\hline Amikacin & 0 & 0 & 0 & 0 & 0 & 0 & 0 \\
\hline Trimethoprim-sulfamethoxazole & $24(11)$ & $6(1)$ & $25(2)$ & $67(4)$ & $100(2)$ & $100(1)$ & $100(1)$ \\
\hline Norfloxacin & $4(2)$ & 0 & $25(2)$ & 0 & 0 & 0 & 0 \\
\hline Levofloxacin & $4(2)$ & 0 & $25(2)$ & 0 & 0 & 0 & 0 \\
\hline
\end{tabular}

isolates had PFGE profiles similar to those of $\mathrm{H}_{2} \mathrm{~S}$-positive strains, as well as to that of $\mathrm{H}_{2} \mathrm{~S}$-negative $S$. Thompson. S. Derby, S. Enteritidis, S. Agona, and $S$. Thompson belonged to ST40, ST11, ST13, and ST26, respectively.
In Group II, pairs of $\mathrm{H}_{2} \mathrm{~S}$-producing and -non-producing $S$. Meleagridis isolated from two samples were grouped in cluster 5; despite different sources, the two pairs had the same PFGE patterns and ST. Cluster 6 contained only one $\mathrm{H}_{2} \mathrm{~S}$-negative $S$. Hadar belonging to

Table 2 Multidrug resistance profiles of eight $\mathrm{H}_{2} \mathrm{~S}$-negative MDR isolates

\begin{tabular}{|c|c|c|c|c|c|c|c|c|c|}
\hline \multirow[t]{2}{*}{ Serotype } & \multirow{2}{*}{$\begin{array}{l}\text { Number of } \\
\text { isolates }\end{array}$} & \multirow{2}{*}{$\begin{array}{l}\text { Antibiotic } \\
\text { resistance profiles }\end{array}$} & \multicolumn{7}{|c|}{ Antimicrobial drug classes } \\
\hline & & & Aminoglycosides & Amphenicols & $\begin{array}{l}\text { Folate } \\
\text { pathway } \\
\text { inhibitors }\end{array}$ & Nitrofurans & Penicillins & Quinolones & Tetracyclines \\
\hline Typhimurium & 1 & $\begin{array}{l}\text { GEN/CHL/SXT/NIT/AMP/ } \\
\mathrm{TIC/TIM/LEV/NOR/TET}\end{array}$ & + & + & + & + & + & + & + \\
\hline Typhimurium & 1 & $\begin{array}{l}\text { GEN/CHL/SXT/AMP/PIP/ } \\
\text { TIC/TIM/LEV/NOR/TET }\end{array}$ & + & + & + & & + & + & + \\
\hline Give & 1 & $\begin{array}{l}\text { GEN/TOB/CHL/SXT/AMP/ } \\
\mathrm{TIC} / \mathrm{TET}\end{array}$ & + & + & + & & + & & + \\
\hline Choleraesuis & 1 & $\begin{array}{l}\text { GEN/CHL/SXT/AMP/PIP/ } \\
\text { TIC/TET }\end{array}$ & + & + & + & & + & & + \\
\hline Choleraesuis & 2 & GEN/SXT/AMP/TIC/TET & + & & + & & + & & + \\
\hline Choleraesuis & 1 & CHL/SXT/AMP/TIC/TET & & + & + & & + & & + \\
\hline Derby & 1 & CHL/SXT/TET & & + & + & & & & + \\
\hline
\end{tabular}




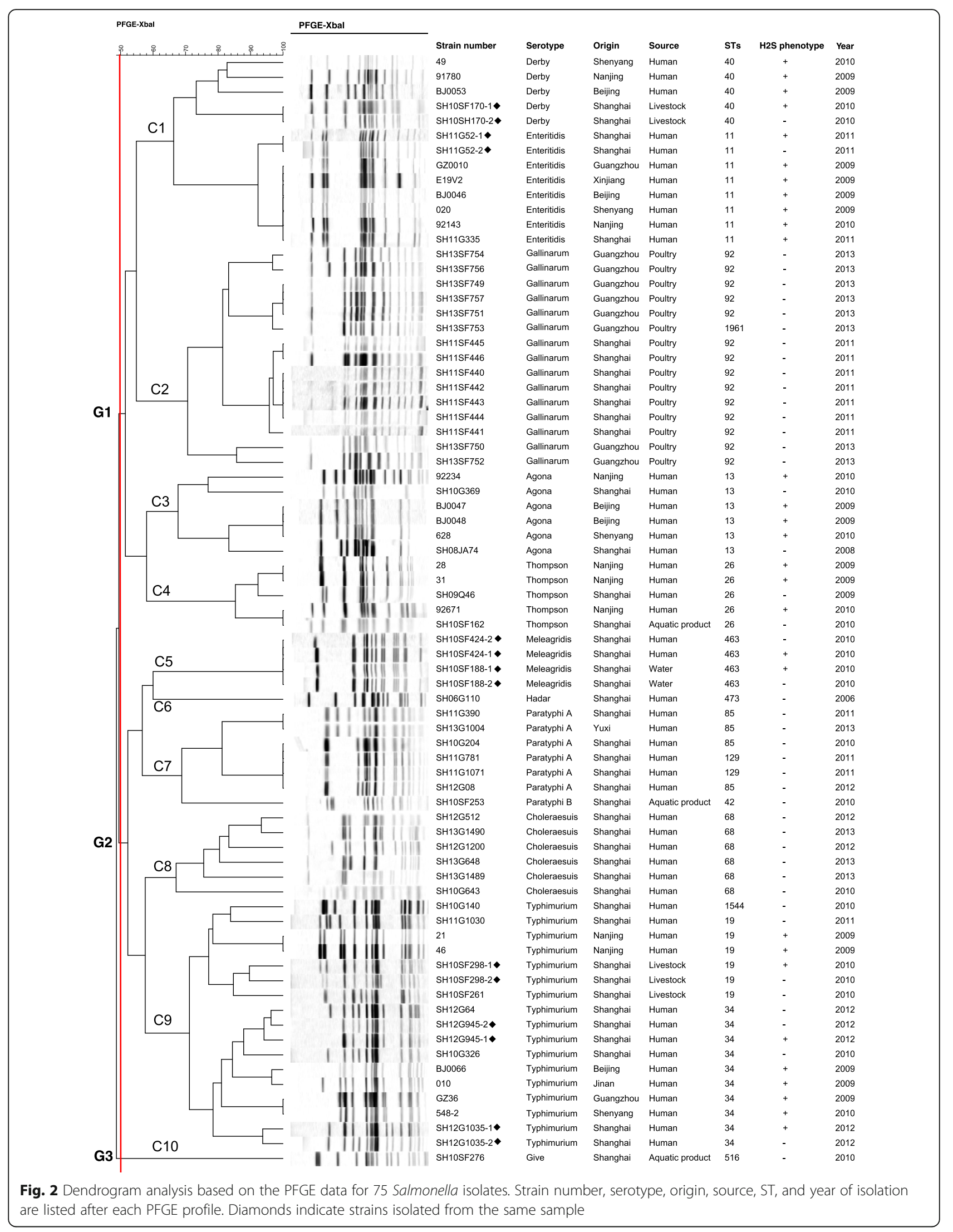


ST473. Cluster 7 was formed by six $\mathrm{H}_{2} \mathrm{~S}$-negative $S$. Paratyphi A and one $\mathrm{H}_{2} \mathrm{~S}$-negative $S$. Paratyphi B isolates. The six $\mathrm{H}_{2} \mathrm{~S}$-negative $S$. Paratyphi A isolates (four ST85 and two ST129) were from humans, andone $\mathrm{H}_{2} \mathrm{~S}$-negative $S$. Paratyphi B belonging to ST42 was from an aquatic product. The six $\mathrm{H}_{2} \mathrm{~S}$-negative $S$. Choleraesuis isolates in cluster 8 had close PFGE patterns, the same $\mathrm{ST}$, and were acquired from the same source and place. In cluster 9, pairs SH10SF298-1 and SH10SF298-2, SH12G945-1 and SH12G945-2, and SH12G1035-1 and SH12G1035-1 were from the same samples, respectively; each pair had very similar banding patterns. Among $S$. Typhimurium $\mathrm{H}_{2} \mathrm{~S}$-negative isolates, six were from humans: four ST34, one ST1544, and one ST19; the former two were SLVs of ST19 and double locus variants (DLVs) of each other.

Finally, Group III consisted of one $\mathrm{H}_{2} \mathrm{~S}$-negative $S$. Give isolate belonging to ST516.

\section{Sequence analysis of the Phs operon}

Previous studies have reported mutations in the phs operon may responsible for the non- $\mathrm{H}_{2} \mathrm{~S}$-producing phenotype in Salmonella [8, 13-15]. In the phsA gene, three different mutation sites were detected among the $46 \mathrm{H}_{2} \mathrm{~S}$-negative Salmonella isolates (Table 3). In S. Gallinarum isolates, missense mutation $1624 \mathrm{C}>\mathrm{T}$ leading to the Leu > Phe substitution was found. In $S$. Choleraesuis isolates, single base deletion 760delG was detected, leading to a frameshift mutation. One $\mathrm{H}_{2} \mathrm{~S}$-negative $S$. Typhimurium (SH10G140) isolate had mutation 1087delA, which caused a frameshift and change in the amino acid sequence. Only few missense mutations were identified in $\mathrm{H}_{2} \mathrm{~S}$-negative $S$. Give and $S$. Hadar (data not shown). However, no mutations in the phsA gene were detected in the remaining 22 isolates (seven $S$. Typhimurium, six $S$. Paratyphi A, two $S$. Agona, two $S$. Meleagridis, two $S$. Thompson, one $S$. Paratyphi B, one $S$. Derby, and one $S$. Enteritidis).

In the phsB gene, we identified only one nonsense mutation in a $S$. Hadar isolate and multiple missense mutations in $S$. Gallinarum isolates. There were four main missense mutation sites, including substitutions $164 \mathrm{~T}>\mathrm{C}$ (eight isolates), 314G $>\mathrm{C}$ (eight isolates), $319 \mathrm{C}>\mathrm{A}$ (11 isolates), and $373 \mathrm{C}>\mathrm{T}$ (eight isolates). In the phs $C$ gene, nonsense and missense mutations

Table 3 Mutations detected in the phsA gene of $\mathrm{H}_{2} \mathrm{~S}$-negative Salmonella isolates

\begin{tabular}{llll}
\hline Serotype & Number of isolates & Mutation & Mutation type \\
\hline Gallinarum & 15 & $\mathbf{1 6 2 4 C}>\mathbf{T}$ & Missense \\
Choleraesuis & 6 & 760delG & Frameshift \\
Typhimurium & 1 & $\mathbf{1 0 8 7 d e I A}$ & Frameshift \\
\hline
\end{tabular}

New mutations are marked bold were found in one $\mathrm{H}_{2} \mathrm{~S}$-negative $S$. Typhimurium and three $\mathrm{H}_{2} \mathrm{~S}$-negative $\mathrm{S}$. Paratyphi A isolates, respectively (Additional file 1 : Table S3).

Sixteen $\mathrm{H}_{2} \mathrm{~S}$-negative isolates carried no mutations in the phs locus ( $p h s A, p h s B$, and $p h s C$ genes).

\section{Discussion}

Although there are few reports about $\mathrm{H}_{2} \mathrm{~S}$-negative Salmonella, the incidence of $\mathrm{H}_{2} \mathrm{~S}$-negative strains is on the rise lately. To the best of our knowledge, $100 \mathrm{H}_{2} \mathrm{~S}$-negative Salmonella isolates of 13 serovars have been reported [6-12]. Moreover, $17 \mathrm{H}_{2} \mathrm{~S}$-negative $S$. Senftenberg isolates, $19 \mathrm{H}_{2} \mathrm{~S}$-negative $S$. Choleraesuis isolates, and seven $\mathrm{H}_{2} \mathrm{~S}$-negative $\mathrm{S}$. Aberdeen isolates were reported in our previous studies [13-15]. In this study, a total of $46 \mathrm{H}_{2} \mathrm{~S}$-negative Salmonella strains belonging to 12 various serovars were isolated from diverse sources across China during 2005-2013. $\mathrm{H}_{2} \mathrm{~S}$-negative $S$. Agona, S. Meleagridis, S. Gallinarum, S. Give, S. Hadar, S. Paratyphi A, $S$. Paratyphi B, and $S$. Thompson were newly identified, indicating that multiple Salmonella serovars could present the non- $\mathrm{H}_{2} \mathrm{~S}$-producing phenotype. Notably, our surveillance data revealed that $52 \%$ strains were isolated from diarrhea patients in hospitals, suggesting that $\mathrm{H}_{2} \mathrm{~S}$-negative Salmonella isolates, similar to $\mathrm{H}_{2} \mathrm{~S}$-positive strains, may play an important role in causing human infections. In addition, food products were another important source of $\mathrm{H}_{2} \mathrm{~S}$-negative Salmonella isolates. It has been reported that 33 Salmonella isolates were identified as $\mathrm{H}_{2} \mathrm{~S}$-negative in 82 retail meat samples from markets in Shenzhen, China [10]. In this study, about $46 \% \mathrm{H}_{2} \mathrm{~S}$-negative Salmonella isolates were from pork, chicken, and aquatic products, suggesting that $\mathrm{H}_{2} \mathrm{~S}$-negative Salmonella could be present in various foods. Since Salmonella isolation methods vary among laboratories and hospitals from different locations, it is possible that the number of $\mathrm{H}_{2} \mathrm{~S}$-negative isolates could be higher than that reported here. Therefore, proposing a standard screening procedure will reduce the missing $\mathrm{H}_{2} \mathrm{~S}$-negative Salmonella during laboratory and hospital screening. In addition, we recommend using API $20 \mathrm{E}$ biochemical test kits and serological testing to further confirm the suspected $\mathrm{H}_{2} \mathrm{~S}$-negative colonies when necessary.

Although a large number of $\mathrm{H}_{2} \mathrm{~S}$-negative Salmonella strains have been reported, their antibiotic resistance patterns were not clarified. Among the $\mathrm{H}_{2} \mathrm{~S}$-negative Salmonella identified in this study, $S$. Choleraesuis exhibited a high rate of antibiotic resistance, comprising $67 \%$ of MDR isolates; similar data on the MDR rate among $\mathrm{H}_{2} \mathrm{~S}$-negative $\mathrm{S}$. Choleraesuis isolates were reported in Japan and in our previous study [7, 14]. To the best of our knowledge, MDR has been previously detected only in $\mathrm{H}_{2} \mathrm{~S}$-negative $S$. Choleraesuis and $S$. 
Kentucky [6, 7]. In this study, the MDR phenotype was observed among $\mathrm{H}_{2} \mathrm{~S}$-negative $S$. Typhimurium, $S$. Give, and $S$. Derby isolates, which were resistant to 11 , seven, and three antibiotics, respectively. In addition, amino acid changes in the GyrA and ParC proteins have been detected in the ciprofloxacin-resistant $\mathrm{H}_{2} \mathrm{~S}$-negative $S$. Kentucky strain and norfloxacin-resistant $\mathrm{H}_{2} \mathrm{~S}$-negativeS. Choleraesuis strains [6]. In this study, we detected mutations in the gyrA and parC genes of $\mathrm{H}_{2} \mathrm{~S}$-negative $S$. Typhimurium strains with complete resistance to quinolones. Cumulatively, these results suggest that the emergence of antibiotic resistance among $\mathrm{H}_{2} \mathrm{~S}$-negative Salmonella strains presents a more serious problem than has been previously anticipated. Although the mechanism of $\mathrm{H}_{2} \mathrm{~S}$-mediated antibiotic resistance has been demonstrate in several bacteria, this process requires anaerobic conditions and antibiotics which have to exert their bactericidal effect by oxidative stress [20, 23, 28]. What's more, plasmid-mediated drug resistance mechanism is responsible for the increased resistance rate to antibiotics as well. Hence, there is a great need to take effective measures to control the prevalence of $\mathrm{H}_{2} \mathrm{~S}$-negative Salmonella isolates with MDR.

Disruption of the phsA gene seems to underlie the lack of $\mathrm{H}_{2} \mathrm{~S}$ production in a large number of $\mathrm{H}_{2} \mathrm{~S}$-negative Salmonella isolates, although mutation analysis was not conducted for all reported $\mathrm{H}_{2} \mathrm{~S}$-negative Salmonella $[8,13-15] . \mathrm{H}_{2} \mathrm{~S}$-negative $S$. Typhimurium and $S$. Infantis have been reported to contain nonsense mutations at positions 1440 and 358 of the phsA gene, respectively [8]. Previously, we identified a frameshift mutation in $\mathrm{H}_{2} \mathrm{~S}$-negative $\mathrm{S}$. Choleraesuis and nonsense mutations in $\mathrm{H}_{2} \mathrm{~S}$-negative $S$. Aberdeen and $S$. Senftenberg [13-15]. In this study, 22 (48\%) $\mathrm{H}_{2} \mathrm{~S}$-negative Salmonella isolates carried mutations at different positions of the phsA gene, indicating that this gene may be responsible for the atypical $\mathrm{H}_{2} \mathrm{~S}$ phenotype. Moreover, we found that phsA mutation sites were serovar-specific, suggesting that serovars containing $\mathrm{H}_{2} \mathrm{~S}$-negative isolates have distinct genetic mechanisms leading to mutations in the phs locus. As the phs operon is essential for the production of $\mathrm{H}_{2} \mathrm{~S}$ from thiosulfate under anaerobic conditions, thiosulfate would concentrate around $\mathrm{H}_{2} \mathrm{~S}$-negative Salmonella cells and react with oxygen species generated during inflammation, producing a new respiratory electron acceptor tetrathionate [29-32]. These studies suggest that the accumulation of thiosulfate by $\mathrm{H}_{2} \mathrm{~S}$-negative Salmonella strains, including $S$. Typhimurium, may provide these strains a growth advantage in competition with other bacteria in the gut lumen, thus presenting a reasonable explanation for the large number of $\mathrm{H}_{2} \mathrm{~S}$-negative Salmonella isolates with high rate of antibiotic resistance detected in humans.

\section{Conclusion}

We identified $46 \mathrm{H}_{2} \mathrm{~S}$-negative Salmonella isolates belonging to 12 serovars in China. As the number of these Salmonella strains has been rapidly increasing over a short period of 9 years, the emergence and prevalence of $\mathrm{H}_{2} \mathrm{~S}$-negative Salmonella cannot be ignored, and special attention should be paid to avoid their further dissemination by implementing specific surveillance measures.

\section{Additional file}

Additional file 1: Table S1. Reference strains for phs operon sequence analysis. Table S2. GenBank accession numbers for phs operon sequences from $46 \mathrm{H}_{2} \mathrm{~S}$-negative Salmonella isolates. Table S3. Mutations detected in the phs $B$ and phs $\mathrm{C}$ genes of $\mathrm{H}_{2} \mathrm{~S}$-negative Salmonella isolates. (DOC $71 \mathrm{~kb}$ )

\section{Abbreviations}

MDR: Multidrug resistance; MLST: Multilocus sequence typing; PFGE: Pulsedfield gel electrophoresis

\section{Funding \\ This work was supported by Beijing Natural Science Foundation (no.7164288), National Key Program for Infectious Diseases of China (nos. AWS15J006 and AWS16J020), and the National Natural Science Foundation of China (nos. 81673237, 81373053, and 81371854). The funders contributed to the study design and data collection.}

\section{Availability of data and materials}

The data sets generated and/or analyzed during the current study are available from the corresponding author on reasonable request.

\section{Authors' contributions}

JX, SQ, and HS conceived and designed the study. FW, JX, and XX performed the experiments. $X Y, R Z, Q M, P L, R H, L W, L J$, and $X D$ analyzed the data. JX wrote the manuscript. All authors have read and approved the final version of the manuscript.

Ethics approval and consent to participate

The study was approved and authorized by the institutional ethics committees of Academy of Military Medical Sciences of the Chinese People's Liberation Army, Beijing, China. The institutional review board of the

Academy of Military Medical Sciences waived the need for written informed consent from the participants.

Consent for publication

Not applicable.

\section{Competing interests}

The authors declare that they have no competing interests.

\section{Publisher's Note}

Springer Nature remains neutral with regard to jurisdictional claims in published maps and institutional affiliations.

\section{Author details}

${ }^{1}$ Institute of Disease Control and Prevention, Academy of Military Medical Sciences, 20 Dongda Street, Fengtai District, Beijing 100071, China. ${ }^{2}$ Shanghai Municipal Center for Disease Control and Prevention, Shanghai, China. 
Received: 1 January 2018 Accepted: 25 June 2018

Published online: 03 July 2018

\section{References}

1. Scallan E, Hoekstra RM, Angulo FJ, Tauxe RV, Widdowson M-A, Roy SL, et al. Foodborne illness acquired in the United States-major pathogens. Emerg Infect Dis. 2011:17:7-15.

2. Behravesh CB, Jones TF, Vugia DJ, Long C, Marcus R, Smith K, et al. Deaths associated with bacterial pathogens transmitted commonly through food: foodborne diseases active surveillance network (FoodNet), 1996-2005. J Infect Dis. 2011:204:263-7.

3. Majowicz SE, Musto J, Scallan E, Angulo FJ, Kirk M, O'Brien SJ, et al. The global burden of nontyphoidal Salmonella gastroenteritis. Clin Infect Dis Off Publ Infect Dis Soc Am. 2010;50:882-9.

4. Mao X, Hu J, Liu X. Estimation on disease burden of foodborne non-typhoid salmonellosis in China using literature review method. Chin J Dis Prev. 2011; 15:622-5.

5. Boadi S, Wren MWD, Morris-Jones S. Selective testing of ß-galactosidase activity in the laboratory identification of Salmonella and Shigella species. J Clin Pathol. 2010;63:1101-4.

6. Albert MJ, Obaid KA, Alfouzan W, Sheikh AR, Udo E, Izumiya H, et al. Isolation of Salmonella enterica Serovar Kentucky strain ST 198 and its H2Snegative variant from a patient: implications for diagnosis. J Clin Microbiol. 2014;52:4090-3.

7. Asai T, Namimatsu T, Osumi T, Kojima A, Harada K, Aoki H, et al. Molecular typing and antimicrobial resistance of Salmonella enterica subspecies enterica serovar Choleraesuis isolates from diseased pigs in Japan. Comp Immunol Microbiol Infect Dis. 2010;33:109-19.

8. Sakano C, Kuroda M, Sekizuka T, Ishioka T, Morita Y, Ryo A, et al. Genetic analysis of non-hydrogen sulfide-producing Salmonella enterica serovar typhimurium and S. Enterica serovar infantis isolates in Japan. J Clin Microbiol. 2013;51:328-30.

9. Xu X, Chen M, Tu L, Sheng Y, Ran L, Diao B, et al. Identification on the epidemic strains of atypical Salmonella enterica subsp. enterica serovar Senftenber. Lab Med. 2010;25:797-800.

10. Lin D, Yan M, Lin S, Chen S. Increasing prevalence of hydrogen sulfide negative Salmonella in retail meats. Food Microbiol. 2014;43:1-4.

11. Kovac J, Cummings KJ, Rodriguez-Rivera LD, Carroll LM, Thachil A, Wiedmann M. Temporal genomic phylogeny reconstruction indicates a geospatial transmission path of Salmonella Cerro in the United States and a clade-specific loss of hydrogen sulfide production. Front Microbiol. 2017:8:737.

12. Abd El Ghany M, Shi X, Li Y, Ansari HR, Hill-Cawthorne GA, Ho YS, et al. Genomic and phenotypic analyses reveal the emergence of an atypical Salmonella enterica Serovar Senftenberg variant in China. J Clin Microbiol. 2016;54:2014-22.

13. Yi S, Xie J, Liu N, Li P, Xu X, Li H, et al. Emergence and prevalence of nonH2S-producing Salmonella enterica serovar Senftenberg isolates belonging to novel sequence type 1751 in China. J Clin Microbiol. 2014;52:2557-65.

14. Xie J, Yi S, Zhu J, Li P, Liang B, Li H, et al. Antimicrobial resistance and molecular investigation of H2S-negative Salmonella enterica subsp. enterica serovar Choleraesuis isolates in China. PLoS One. 2015;10:e0139115.

15. Wu F, Xu X, Xie J, Yi S, Wang J, Yang X, et al. Molecular characterization of Salmonella enterica Serovar Aberdeen negative for $\mathrm{H} 2 \mathrm{~S}$ production in China. PLoS One. 2016;11:e0161352.

16. Li Y, Xie X, Xu X, Wang X, Chang H, Wang C, et al. Nontyphoidal salmonella infection in children with acute gastroenteritis: prevalence, serotypes, and antimicrobial resistance in shanghai, China. Foodborne Pathog Dis. 2014;11: 200-6.

17. Kuo H-C, Lauderdale T-L, Lo D-Y, Chen C-L, Chen P-C, Liang S-Y, et al. An association of genotypes and antimicrobial resistance patterns among Salmonella isolates from pigs and humans in Taiwan. PLoS One. 2014;9: e95772

18. Kariuki S, Onsare RS. Epidemiology and genomics of invasive Nontyphoida Salmonella infections in Kenya. Clin Infect Dis Off Publ Infect Dis Soc Am. 2015;61(Suppl 4):S317-24.

19. Kwambana-Adams B, Darboe S, Nabwera H, Foster-Nyarko E, Ikumapayi UN, Secka O, et al. Salmonella Infections in The Gambia, 2005-2015. Clin Infect Dis Off Publ Infect Dis Soc Am. 2015;61(Suppl 4):S354-62.

20. Shatalin K, Shatalina E, Mironov A, Nudler E. H2S: a universal defense against antibiotics in bacteria. Sci. 2011;334:986-90.
21. Clark MA, Barrett EL. The phs gene and hydrogen sulfide production by Salmonella typhimurium. J Bacteriol. 1987;169:2391-7.

22. Huang CJ, Barrett EL. Sequence analysis and expression of the Salmonella typhimurium asr operon encoding production of hydrogen sulfide from sulfite. J Bacteriol. 1991;173:1544-53.

23. Álvarez R, Neumann G, Frávega J, Díaz F, Tejías C, Collao B, et al. CysBdependent upregulation of the Salmonella typhimurium cysJIH operon in response to antimicrobial compounds that induce oxidative stress. Biochem Biophys Res Commun. 2015;458:46-51.

24. Fong CL, Heinzinger NK, Tongklan S, Barrett EL. Cloning of the phs genetic locus from Salmonella typhimurium and a role for a phs product in its own induction. J Bacteriol. 1993;175:6368-71.

25. CLSI. Performance standards for antimicrobial susceptibility testing; twentysecond informational supplement. CLSI document M100-S22. Wayne: Clinical and Laboratory Standards Institute; 2012.

26. Ribot EM, Fair MA, Gautom R, Cameron DN, Hunter SB, Swaminathan B, et al. Standardization of pulsed-field gel electrophoresis protocols for the subtyping of Escherichia coli 0157:H7, Salmonella, and Shigella for PulseNet. Foodborne Pathog Dis. 2006;3:59-67.

27. Hunter SB, Vauterin P, Lambert-Fair MA, Van Duyne MS, Kubota K, Graves L, et al. Establishment of a universal size standard strain for use with the PulseNet standardized pulsed-field gel electrophoresis protocols: converting the national databases to the new size standard. J Clin Microbiol. 2005;43: 1045-50.

28. Frávega J, Álvarez R, Díaz F, Inostroza O, Tejías C, Rodas PI, et al. Salmonella typhimurium exhibits fluoroquinolone resistance mediated by the accumulation of the antioxidant molecule $\mathrm{H} 2 \mathrm{~S}$ in a CysK-dependent manner. J Antimicrob Chemother. 2016;71:3409-15.

29. Levitt MD, Furne J, Springfield J, Suarez F, DeMaster E. Detoxification of hydrogen sulfide and methanethiol in the cecal mucosa. J Clin Invest. 1999; 104:1107-14.

30. Stecher B, Robbiani R, Walker AW, Westendorf AM, Barthel M, Kremer M, et al. Salmonella enterica serovar typhimurium exploits inflammation to compete with the intestinal microbiota. PLoS Biol. 2007:5:2177-89.

31. Thiennimitr P, Winter SE, Winter MG, Xavier MN, Tolstikov V, Huseby DL, et al. Intestinal inflammation allows Salmonella to use ethanolamine to compete with the microbiota. Proc Natl Acad Sci. 2011;108:17480-5.

32. Winter SE, Thiennimitr P, Winter MG, Butler BP, Huseby DL, Crawford RW, et al. Gut inflammation provides a respiratory electron acceptor for Salmonella. Nat. 2010:467:426-9.

\section{Ready to submit your research? Choose BMC and benefit from:}

- fast, convenient online submission

- thorough peer review by experienced researchers in your field

- rapid publication on acceptance

- support for research data, including large and complex data types

- gold Open Access which fosters wider collaboration and increased citations

- maximum visibility for your research: over $100 \mathrm{M}$ website views per year

At BMC, research is always in progress.

Learn more biomedcentral.com/submissions 